\title{
Immunohistochemical assessment of CD l a-positive Langerhans cells and their relationship with E-cadherin in minor salivary gland tumors
}

\author{
Fátima Karoline Araújo Alves Dultra ${ }^{1}$, Adna Conceição Barros ${ }^{1}$, Helenemarie Schaer-Barbosa ${ }^{2}$, \\ Andréia Leal Figueiredo ${ }^{3}$, Clarissa Araújo Silva Gurgel ${ }^{4}$, Eduardo Antônio Gonçalves Ramos ${ }^{4}$, \\ Ana Maria da Silva Carvalho ${ }^{4}$, Jean Nunes dos Santos ${ }^{1}$
}

${ }^{1}$ Laboratory of Oral Surgical Pathology, Department of Oral Pathology, School of Dentistry, Federal University of Bahia, Salvador, Bahia, Brazil; ${ }^{2}$ Department of Pathology, Aristides Maltez Hospital, Salvador, Bahia, Brazil; ${ }^{3}$ Department of Dental Public Health, School of Dentistry, Federal University of Bahia, Salvador, Bahia, Brazil; ${ }^{4}$ Laboratory of Pathology and Biology Molecular, Oswaldo Cruz Foundation, Salvador, Bahia, Brazil

\begin{abstract}
OBJECTIVE: The aim of this study was to investigate the presence of CDIa-positive Langerhans cells and their relationship with E-cadherin in minor salivary gland tumors.

METHODS: Twenty-seven minor salivary gland tumors were investigated using immunohistochemistry for CD Ia and E-cadherin.

RESULTS: A significant difference regarding the mean density of CDIa-positive Langerhans cells was observed between pleomorphic adenomas and malignant tumors studied $(P=0.00 \mathrm{I})$. No CDIa-positive cells were detected in most cases $(n=5)$ of cystic adenoid carcinomas. CDIa-positive cells were detected in one mucoepidermoid carcinoma case, and six low-grade polymorphous adenocarcinomas cases. Comparison of the mean density of CDIa-positive cells between the three malignant tumors showed no significant difference $(P=0.127)$. No significant difference was observed in the presence of E-cadherin between tumors $(P=\mathbf{0 . 7 3})$, but it was detected in 24 cases.

CONCLUSIONS: The lack of CD l a-positive in malignant salivary gland tumors facilitates the neoplastic development and suggests that these cells might be useful as auxiliary diagnostic and prognostic tool in minor salivary gland tumors. Furthermore, it is suggested that E-cadherin mediates cell adhesion in these tumors although we did not demonstrate significance.

J Oral Pathol Med (20I2) 4I: 47-53
\end{abstract}

Keywords: cell adhesion; dendritic cell; immunohistochemistry; salivary gland tumors

Correspondence: Jean Nunes dos Santos, Avenida Araújo Pinho, 62, Canela, Salvador-BA 40110-150, Brazil. Tel: 55713283 9019, Fax: 55713283 8962, E-mail: jeanunes@ufba.br

Accepted for publication April 20, 2011

\section{Introduction}

Salivary gland tumors are an important group of oral neoplasms, with those originating from the minor salivary gland accounting for $9-23 \%$ of all salivary gland tumors $(1,2)$. Despite their low frequency, salivary gland tumors present a diverse biological behavior as a result of their cytoarchitectural complexity $(3,4)$. Therefore, various studies have focused on predicting the course of these tumors (5-7).

Langerhans cells are immature dendritic cells residing in epithelial tissue that play a fundamental role in the presentation of tumor antigens to $\mathrm{T}$ cells inside lymph nodes, thereby eliciting an antitumor response (8-11). Various investigators have demonstrated that tumors expressing high numbers of Langerhans cells present a better prognosis $(8,11-14)$. In this respect, immune surveillance against neoplastic proliferation is a complex process that has raised interest on the part of researchers (15).

E-cadherin is a calcium-dependent glycoprotein responsible for the adhesion between epithelial cells whose main function is related to the morphogenesis and maintenance of the integrity of epithelial tissue (1619). Previous studies have shown that the absent or reduced expression of E-cadherin is associated with the loss of differentiation, invasion, and metastasis of epithelial tumors involving different anatomic sites, including head and neck tumors (20-23). In addition, E-cadherin mediates the adhesion between Langerhans cells and keratinocytes $(18,19)$.

Little is known about the role of Langerhans cells (24, $25)$ and E-cadherin $(20,26,27)$ in minor salivary gland tumors. Therefore, the aim of the present study was to investigate the presence of CD1a-positive Langerhans cells and their relationship with E-cadherin in minor salivary gland tumors. 


\section{Material and methods}

After approval by the Institutional Ethics Committee, 27 patients with minor salivary gland tumors (seven pleomorphic adenomas; seven adenoid cystic carcinomas; seven mucoepidermoid carcinomas; six low-grade polymorphous adenocarcinomas) were selected from the archives of the Surgical Pathology Service, School of Dentistry, Federal University of Bahia, and Department of Pathology, Aristides Maltez Hospital, Salvador, Bahia, Brazil. Clinical data obtained from the request forms of the anatomopathological exams indicated that 21 patients were females and 06 were males, with a mean age of 51 years.

For morphological analysis, the formalin-fixed and paraffin-embedded material was cut into $4-\mu \mathrm{m}$-thick sections. After staining with hematoxylin eosin, the material was reviewed by an experienced pathologist and classified according to the histological criteria defined by World Health Organization (WHO) (28).

Immunohistochemistry was performed on paraffin wax-embedded sections (3- $\mu \mathrm{m}$ thick). The tissue sections were deparaffinized and rehydrated using routine methods. For CD1a, heat-induced antigen retrieval was performed (boiling the sections in EDTA, $\mathrm{pH}$ 8.0, for $30 \mathrm{~min}$ at $97^{\circ} \mathrm{C}$ ). The same antigen retrieval technique was used for E-cadherin, but the sections were boiled in citrate monohydrate solution, $\mathrm{pH}$ 6.9. Endogenous peroxidase activity was blocked by immersion of the tissue sections in phosphate-buffered saline containing $0.3 \%$ hydrogen peroxide. Next, monoclonal antibodies against CD1a (clone MTB1; Novocastra, Newcastle, UK; dilution 1:30) and E-cadherin (clone $\mathrm{NCH}-38$; Dako Cytomation, Glostrup, Denmark; dilution 1:50) were applied using the EnVision ${ }^{\mathrm{TM}}$ System (Dako Corporation, Carpinteria, CA, USA). The sections were incubated with the antibodies for $30 \mathrm{~min}$ at room temperature. The immunohistochemical reactions were developed with 3'3-diaminobenzidine (Dako Corporation) as chromogenic peroxidase substrate, and the slides were counterstained with Mayer's hematoxylin. Normal glandular tissue adjacent to the tumor, lining epithelium and one pyogenic granuloma case served as positive controls. The negative control consisted of replacement of the primary antibody with an antibody of the same isotype.

CD1a- and E-cadherin-positive cells were analyzed by a previously trained observer by light microscopy. The examiner was blind to the microscopic diagnosis and previous value of total count.

CD1a-positive cells were counted in up to five microscopic fields at a final magnification of $200 \times$, considering cells present inside the stroma and tumor parenchyma. For this analysis, the slides were examined with a light microscope coupled to a digital camera system (AXIOCAM ICC3; 2008, ZEISS, Goetingen, Germany) using a software (Axio Vision 4.8; ZEISS, Goetingen, Germany, 2008). The shape of the cells was also described.

For E-cadherin, cases were assigned to one of the following criteria: score 0 , no staining; score 1 , weak staining; score 2, moderate staining; and score 3, strong straining). The proportion of staining was defined as the percentage of labeled cells $(0,0 \% ; 1,1-25 \% ; 2,25-75 \%$; and $3,>75 \%)$. Multiplication of intensity $(0-3)$ by proportion ( 0 to $>75 \%$ ) resulted in a following score: when $<25 \%$ of the cells were labeled or the immunostaining intensity was weak, the product of the two scores was until 3 and expression was classified as negative. When at least $25 \%$ of the cells were labeled and the immunolabeling intensity was moderate or strong, the product of the two scores was at least four and expression was classified as positive.

Differences between groups were tested using the Kruskal-Wallis, chi-square, and Mann-Whitney tests. The correlation between CD1a and E-cadherin was analyzed using Spearman's correlation coefficient. All statistical calculations were performed using SPSS 13.0 program (Chicago, IL, USA). A $P$ value $<0.05$ was considered to be statistically significant.

\section{Results}

CDla-positive cells were detected in 15 minor salivary gland tumors studied (Fig. 1). CD1a immunostaining was highly heterogenous among the different histological types of tumors and even within the same histological type (Table 1). For comparative analysis, well-differentiated glandular tissue was used, which did not contain CD1a-positive cells, as well as surface epithelium with marked number of CD1a-positive cells.

In pleomorphic adenomas $(n=7)$, despite the observation of one tumor with few CD1a-positive cells, most cases showed a significant mean density which was higher than that observed for the other malignant neoplasms ( $P=0.001$, Kruskal-Wallis test). There was a predominance of the dendritic shape. CD1a-positive cells were detected inside the tumor parenchyma, around ducts, and amidst myoepithelial cells and close to blood vessels. Dendritic or round cells were eventually observed in the peritumor zone, but CD1a-positive cells were generally absent in the extracellular matrix (Fig. 1A-C). The presence of inflammation was clearly visible in areas with a higher concentration of CD1apositive cells, but that phenomenon was not common. A significant difference in the mean density of CDlapositive cells was observed between the pleomorphic adenomas and the group of malignant tumors ( $P=0.000$, Mann-Whitney test $)$, especially when compared with mucoepidermoid carcinomas $(P=0.02$, Mann-Whitney test).

In contrast, no CD1a-positive cells were detected in most cases $(n=5)$ of adenoid cystic carcinoma (two cases of the tubular type and three cases of the cribriform type). When present, these cells showed a more dendritic shape and were located in cribriform areas, cords, and more solid cellular nests and, eventually, in outer most cells of the tubular structures; CD1apositive cells were also detected in isolated tumor cells. Stromal immunostaining was observed in one case which showed dendritic-shaped CD1a-positive cells were in areas close to the tumor parenchyma 

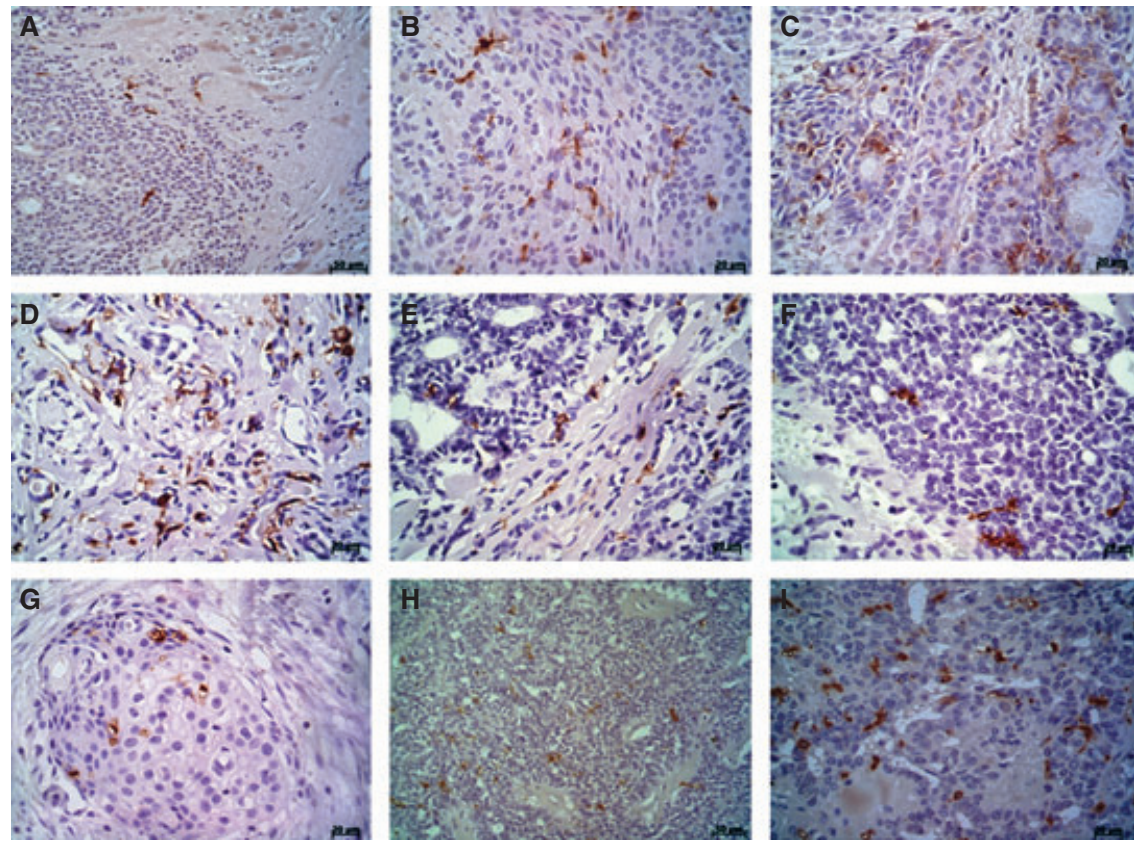

Figure 1 Pleomorphic Adenoma: CDla-positive cells located in the extracellular matrix close to tumor parenchyma and amidst ovoid to plasmacytoid cells (A). Solid area composed of plasmacytoid cells displaying accumulation of CDla-positive dendritic cells (B). Tubulo-trabecular areas displaying of CD1a-poisitive dendritic cells (C). Adenoid Cystic Carcinoma: Pseudocystic spaces formed by tumor cells and displaying CD1apositive cells; note isolated cells expressing CDla-positive cells (D). CDla-positive dendritic cells located in the extracellular matrix close to and within tumor parenchyma (E). Solid area with few CDla-positive dendritic cells (F). Mucoepidermoid Carcinoma: Small solid structure composed of epidermoid cells displaying a few CDla-positive cells (G). Polymorphous Low-Grade Adenocarcinoma: CDla-positive dendritic cells scattered in solid growth with tubular formations $(\mathrm{H})$. Tumor cells with isomorphic and bland nuclei expressing CDla-positive dendritic cells mainly around small tubular formations (I).

Table 1 Variations in number of CDla-positive cells in minor salivary gland tumors

\begin{tabular}{|c|c|c|c|c|}
\hline & $\begin{array}{l}\text { Pleomorphic } \\
\text { adenoma } \\
\text { Mean }(S D)\end{array}$ & $\begin{array}{l}\text { Cystic adenoid } \\
\text { carcinoma } \\
\text { Mean }(S D)\end{array}$ & $\begin{array}{l}\text { Mucoepidermoid } \\
\text { carcinoma } \\
\text { Mean }(S D)\end{array}$ & $\begin{array}{c}\text { low-grade polymorphous } \\
\text { adenocarcinomas } \\
\text { Mean }(S D)\end{array}$ \\
\hline CD1a-positive cells & $17.87(9.07)$ & $2.48(4.75)$ & $0.71(1.88)$ & $2.83(2.59)$ \\
\hline
\end{tabular}

(Fig. 1D-F). This case also presented areas of chronic inflammation and formation of lymphoid follicles.

CD1a-positive cells were detected in one mucoepidermoid carcinoma. These cells were dendritic and were located in areas corresponding to the tumor parenchyma that consisted of intermediate and epidermoid cells (Fig. 1G), as well as in some glandular ducts close to areas of chronic inflammation. Calcification and clear cells were observed in some of the negative cases. All cases were low-grade mucoepidermoid carcinomas.

CD1a-positive cells were detected in six low-grade polymorphous adenocarcinomas (Fig. 1H,I). The mean density of these cells was higher than that observed in adenoid cystic carcinomas and mucoepidermoid carcinomas. In addition, despite a predominance of dendritic-shaped cells, round cells were also observed. Absence of immunostaining was seen in many fields of these tumors, although a marked concentration of these cells could be observed in other fields within the same tumor. CD1a-positive cells were mainly found inside the tumor parenchyma, with the observation of staining in solid nests and cellular cords, as well as in ducts and in the periductal region. In some cases, round cells predominated in the stroma and tumor parenchyma.

Comparison of the mean density of CDla-positive cells between the three malignant tumors studied showed no significant difference $(P=0.127$, KruskalWallis test).

Although no significant difference was observed in the presence of E-cadherin between the groups of tumors $(P=0.73$, chi-square test), this adhesion molecule was detected in the membrane and cytoplasm of $24(89 \%)$ of the 27 patients with minor salivary gland tumors studied (Fig. 2). The intensity of staining ranged from moderate to strong in most cases, although heterogeneous staining could be seen within the same tumor. With respect to the percentage of stained cells, $50 \%$ of the tumors presented more than $50 \%$ stained cells, with no significant difference between groups $(P=0.471$, chi-square test $)$.

Immunostaining for E-cadherin was not detected in all patients with pleomorphic adenoma and, if present, was restricted to some cellular components of the 

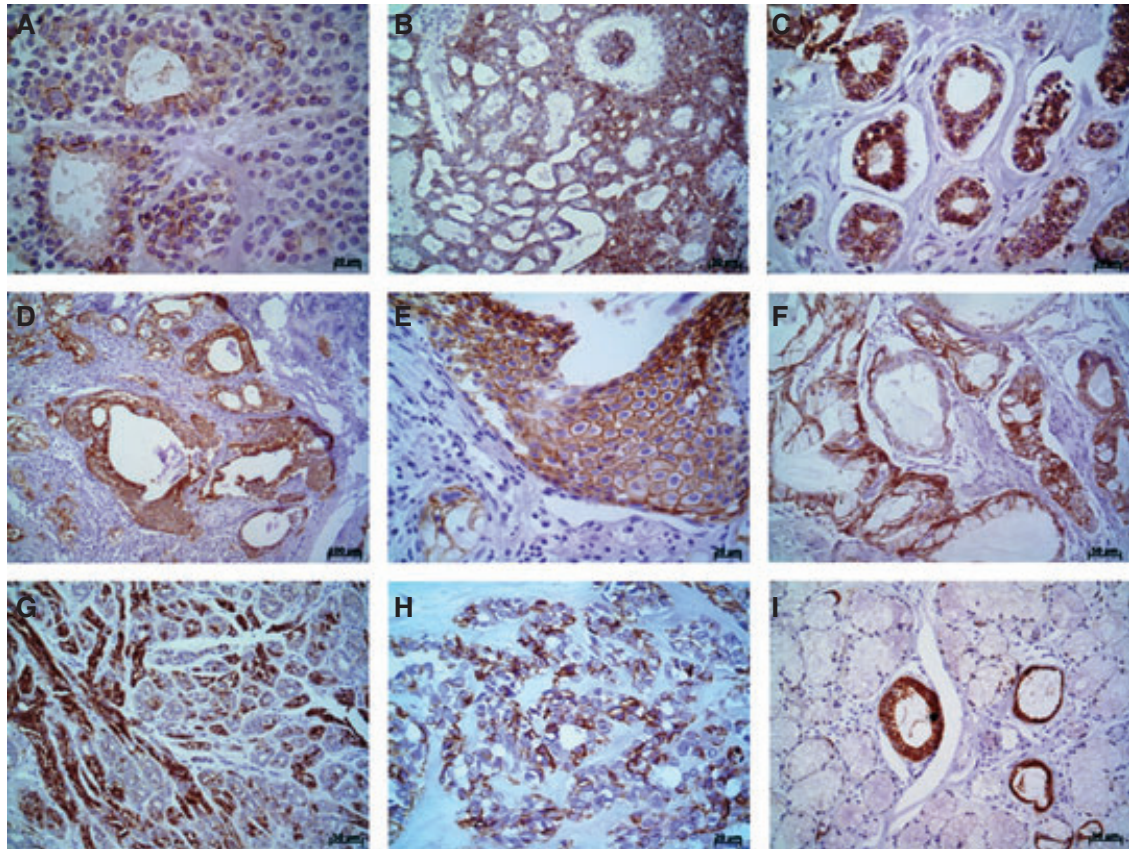

Figure 2 Pleomorphic Adenoma: Weak-to-moderate expression of E-cadherin in luminal and extraluminal cells of ductal areas; note absent or weak staining was detected in areas corresponding to myoepithelial cells (A). Adenoid Cystic Carcinoma: Basaloid and cuboidal cells exhibiting loss of immunostaining from periphery to the center (B). Tubular pattern exhibiting strong membranous immunostaining (C). Mucoepidermoid Carcinoma: Cystic spaces lined by intermediate and epidermoid cells showing strong-to-moderate immunostaining of E-cadherin (D). High-power view showing intermediate cells with membranous and cytoplasmatic immunostaining (E). Papillary cystic growth showing variable immunostaining of E-cadherin (F). Polymorphous Low-Grade Adenocarcinoma: Tubulo-trabecular areas and small tubular formations showing strong immunostaining of E-cadherin; note loss of immunostaining in some areas $(\mathrm{G})$. Some tumor cells with isomorphic and bland nuclei are expressing strong immunostaining for E-cadherin $(\mathrm{H})$. Normal salivary gland with striated ducts and mucous acini showing variable expression of E-cadherin (I).

parenchyma of each tumor. Staining was observed in luminal and extraluminal cells of ductal structures (Fig. 2A). Absent or weak staining was detected in areas corresponding to myoepithelial cells.

In adenoid cystic carcinomas, strong immunostaining was detected in the more central portion of tumor islands, but a loss of expression was generally noted (Fig. 2B). Positive staining was detected in tubular areas (luminal and extraluminal cells) (Fig. 2C), but not always were all cells stained. In cribriform areas, stronger staining was observed at the periphery of some epithelial blocks, which became weaker with decreasing distance from the center. Variable staining was also observed in more solid areas of the tumor and was often concentrated at the periphery, becoming weaker with decreasing distance from the center of the tumor.

In mucoepidermoid carcinoma cases, E-cadherin staining was observed around cystic spaces lined with epidermoid (Fig. 2D), intermediate (Fig. 2E), and mucosal cells (Fig. 2F). However, as observed for the other tumors, the pattern of immunostaining was heterogenous, with the detection of positive and negative cells in the same tumor.

Visible heterogeneity in E-cadherin immunostaining was observed in the low-grade polymorphous adenocarcinomas, being observed loss of immunostaining in more than $50 \%$ o the tumor population. Immunostaining was detected around tubules, cords, and even solid areas as well as in tubulo-trabecular areas (Fig. 2G,H). In addition, loss or absence of immunostaining could be observed within the same tumor that showed immunopositive cells.

Normal glandular tissue adjacent to the tumor was strongly stained around glandular ducts, whereas variable staining was observed around glandular acini (Fig. 2I). Normal oral epithelium, if present, was also stained.

Comparison of the percentage of E-cadherin-positive cells between the group of malignant tumors and pleomorphic adenoma revealed no significant difference $(P=0.534$, chi-square test). There was also no difference in the intensity of immunostaining between the tumors studied ( $P=0.612$, chi-square test). Spearman's correlation test showed no significant correlation between the presence or absence of E-cadherin and the number of CD1a-positive cells ( $P=0.401)$. A summary of scores regarding E-cadherin is presented in Table 2.

\section{Discussion}

Few studies have investigated CD1a-positive Langerhans cells in minor salivary gland tumors (29). The present study analyzed the presence of these cells and the expression of E-cadherin, an important adhesion molecule for tissue integrity and the maintenance of Langerhans cells, in a series of minor salivary gland 
Table 2 Score of immunostaining and labeled cells of E-cadherin in minor salivary gland tumors

\begin{tabular}{|c|c|c|c|c|}
\hline \multirow[b]{2}{*}{ Tumor groups } & \multicolumn{4}{|c|}{ Immunostaining intensity } \\
\hline & Score 0 (n) & Score 1 (n) & Score 2 (n) & Score $3(\mathrm{n})$ \\
\hline Pleomorphic adenoma & 0 & 1 & 3 & 3 \\
\hline Adenoid cystic carcinoma & 0 & 1 & 1 & 5 \\
\hline Mucoepidermoid carcinoma & 1 & 2 & 1 & 3 \\
\hline \multirow[t]{3}{*}{ Low grade polymorphous adenocarcinoma } & 2 & 1 & 2 & 1 \\
\hline & \multicolumn{4}{|c|}{ Labelled cells } \\
\hline & Score 0 (n) & Score $1(\mathrm{n})$ & Score 2 (n) & Score $3(\mathrm{n})$ \\
\hline Pleomorphic adenoma & 0 & 2 & 3 & 2 \\
\hline Adenoid cystic carcinoma & 0 & 2 & 2 & 3 \\
\hline Mucoepidermoid carcinoma & 1 & 1 & 3 & 2 \\
\hline \multirow[t]{3}{*}{ Low grade polymorphous adenocarcinoma } & 2 & 1 & 1 & 2 \\
\hline & \multicolumn{4}{|c|}{ Immunostaining intensity vs. Labelled Cells } \\
\hline & \multicolumn{2}{|c|}{ Negative Cases (n) } & \multicolumn{2}{|c|}{ Positive Cases (n) } \\
\hline Pleomorphic adenoma & \multicolumn{2}{|c|}{1} & \multicolumn{2}{|c|}{6} \\
\hline Adenoid cystic carcinoma & \multicolumn{2}{|c|}{2} & \multicolumn{2}{|c|}{5} \\
\hline Mucoepidermoid carcinoma & \multicolumn{2}{|c|}{4} & \multicolumn{2}{|c|}{3} \\
\hline Low grade polymorphous adenocarcinoma & \multicolumn{2}{|c|}{4} & \multicolumn{2}{|c|}{2} \\
\hline
\end{tabular}

tumors $(30,31)$. To our knowledge, this is the first study investigating the simultaneous presence of CDla-positive Langerhans cells and E-cadherin in minor salivary gland tumors.

The present results showed the absence of CD1apositive cells in different cases of malignant salivary gland tumors. If present, immunostaining for these cells was scarce and heterogenous. This finding might explain the high rate of recurrence and metastasis of many of these malignant tumors $(32,33)$. According to Gabrilovich et al. (34); Oyama et al. (35), the scarcity or absence of dendritic cells in some tumors might be related to the lack of recruitment of these cells or their insufficient development as the result of the action of VEGF produced by many tumors, which interferes with the differentiation of dendritic cells by inhibiting the activation of NF-kß.

A high density of CD1a-positive cells was statistically significant observed in pleomorphic adenomas compared with the other malignant tumors studied, with the lowest density being detected in mucoepidermoid carcinomas. Despite this, the marked presence of these cells in pleomorphic adenomas might be useful as auxiliary diagnostic tool to establish differences between benign and malignant minor salivary gland tumors, as inhibition of the expression of CD1a-positive cells is a mechanism used by malignant tumors to escape the antitumor immune response (36).

In the tumors studied here, the higher density of CDla-positive cells seen in pleomorphic adenomas and low-grade polymorphous adenocarcinomas compared with the other malignant tumors may also be attributed to the degree of tumor differentiation, as these tumors are more differentiated and present a lower rate of recurrence and metastasis, respectively $(37,38)$. On the other hand, it is possible that the myoepithelial content may influence the higher density of CD1a-positive cells in both tumors.

Despite the presence of areas of inflammation in a few cases of pleomorphic adenoma, adenoid cystic carcinoma and mucoepidermoid carcinoma, it is important to state that the majority of tumors studied showed no inflammation. In addition, the mean density of CD1a-positive cells was higher in almost all patients with low-grade polymorphous adenocarcinoma compared with cystic adenoid carcinomas and mucoepidermoid carcinomas, and inflammation was not observed in any case of LGPA. Taken together, the depletion of CD1a-positive cells in minor salivary gland tumors impairs the host's immune surveillance and thus favors the progression of these tumors.

David and Buchner (39) reported a case of pleomorphic adenoma of the submandibular gland and only found Langerhans cells in areas of squamous metaplasia. In this study, most CD1a-positive cells were located inside the tumor parenchyma and, when observed in the extracellular matrix, were present in the periparenchymal region. According to Al-Shibli et al. (40), in non-small cell lung cancer, CDla-positive cells are more abundant in the stroma of well-differentiated tumors, a finding that might be a direct response of the interaction of these cells with lymphocytes infiltrating the tumor to elicit an antitumor response. However, the opposite was demonstrated by Inoshima et al. (41).

In contrast to the results of the present study, Wischatta et al. (29) found no CDla-positive cells or other markers in parotid gland tumors. However, despite the participation of Langerhans cells in the antitumor response, some studies have provided such evidence. Laguens et al. (8) compared the density of S100-, CD86-, and CD1a-positive dendritic cells between tumor-free regional lymph nodes of patients with malignant epithelial tumors and lymph nodes of patients without malignancies and observed a reduction in CD1a- and S-100-positive cells in the former. According to these authors, this finding may indicate the production of immunosuppressive factors that block the maturation and early apoptosis of dendritic cells. Taube 
et al. (42) showed a reduced density of S100-positive Langerhans cells in HIV-positive patients with highgrade vulvar intraepithelial neoplasia compared with HIV-negative patients, a fact that may contribute to the progression of human papilloma virus-related vulvar lesions. In the study of Eisenthal et al. (43) investigating the presence of HLA-DR and CD1a-positive dendritic cells in ovarian cancer biopsy specimens of patients followed up for a period of 10-37 months, nine patients had no evidence of disease during this period and nine patients presented recurrence. The mean number of dendritic cells was substantially higher in the first group. La Rocca et al. (10) observed that the higher the infiltration of CD1a-positive dendritic cells in primary invasive ductal breast carcinoma, the lower the possibility of lymph node metastases, suggesting that CD1apositive cells might be a favorable prognostic marker in these tumors. Taken together, these results suggest that dendritic cells might be used as a prognostic marker in malignant tumors.

In the present study, E-cadherin was detected at a higher or lower proportion in almost all salivary gland tumors studied, but no significant difference could be observed (44). It was therefore not possible to attribute the lower density or absence of CD1a-positive cells to a lower expression of E-cadherin. These results are similar to those reported by Furuse et al. (26) and Econopoulou et al. (20) who demonstrated the expression of E-cadherin in all salivary gland tumors studied, but disagree with the findings of Prabhu et al. (27) who observed a significant difference in the expression of E-cadherin between benign and malignant salivary gland tumors. It is important to state that altered expression of E-cadherin is associated with a lower degree of differentiation, acquisition of an invasive phenotype, and a poor clinical course in many types of cancer (31). However, the present study failed to demonstrate such association, although the opposite has been reported for salivary gland tumors including adenoid cystic carcinoma $(9,45)$.

In pleomorphic adenomas, E-cadherin staining was observed in glandular ducts, whereas no or weak immunostaining was detected in myoepithelial cells. Similar findings have been reported by Econopoulou et al. (20), whereas Furuse et al. (26) also found variable staining in myoepithelial cells. Similar to the findings of Prabhu et al. (27), moderate-to-strong immunostaining was observed in cases of adenoid cystic carcinoma and mucoepidermoid carcinoma. In cystic adenoid carcinoma, immunostaining was mainly observed at the periphery of tumor islands, with a loss of immunostaining in more central areas of the cribriform patterns, whereas in mucoepidermoid carcinoma, the expression of E-cadherin was not uniform as also reported by Shieh et al. (46). Heterogenous immunostaining for E-cadherin was observed in low-grade polymorphous adenocarcinomas when compared with the other tumors studied, with a marked loss of E-cadherin expression in small nests and large islands. Despite this variability in the expression levels of E-cadherin, Araújo et al. (47) suggested that reduced levels of E-cadherin and beta-catenin in invasive areas of carcinoma ex pleomorphic adenoma might be associated with cell migration and not with increased proliferation.

The expression of E-cadherin is markedly reduced in the presence of migration and maturation of epidermal Langerhans cells, and low levels of this protein on the surface of Langerhans cells have been correlated with reduced cellular adhesion in vitro (30). The present study was unable to demonstrate the influence of E-cadherin on the maintenance of CD1a-positive dendritic cells using this methodology. However, we believe that the interaction between CD1a-positive dendritic cells and neoplastic epithelial cells mediated by E-cadherin is important for the induction of local immunity in minor salivary gland tumors.

Finally, the lack of CD1a-positive cells in malignant salivary gland tumors impairs the presentation of tumor antigens and consequently facilitates neoplastic development, a finding indicating that these cells might be useful as auxiliary diagnostic and prognostic tool in minor salivary gland tumors. In addition, although we did not demonstrated significance using E-cadherin, other adhesion molecules of the E-cadherin complex should be investigated as it seems that this molecule is unable to maintain CD1a-positive cells in the glandular epithelium for a period of time sufficient for these cells to exert their function. However, the results suggest that E-cadherin mediates cell adhesion in minor salivary gland tumors.

\section{References}

1. Eveson JW, Cawson RA. Salivary gland tumors. A review of 2410 cases with particular reference to histological types, site, age, and sex distribution. J Pathol 1985; 146: $51-8$.

2. Waldron CA, El-Mofty K, Gnepp DR. Tumors of the intraoral minor salivary glands: a demographic and histologic study of 426 cases. Oral Surg Oral Med Oral Pathol 1988; 66: 323-33.

3. Yih WY, Kratochvil FJ, Stewart JC. Intraoral minor salivary gland neoplasms: review of 213 cases. Int J Oral Maxillofac Surg 2005; 63: 805-10.

4. Beltran D, Faquen VC, Gallagher G, August M. Selective immunohistochemical comparison of polymorphous lowgrade adenocarcinoma and adenoid cystic carcinoma. J Oral Maxillofac Surg 2006; 64: 415-23.

5. Ben-Izhak O, Akrish S, Nagler RM. Ki-67 and salivary cancer. Cancer Invest 2008; 26: 1015-23.

6. Demasi AP, Costa AF, Altemani A, Furuse C, Araújo NS, Araújo VC. Glucose transporter protein 1 expression in mucoepidermoid carcinoma of salivary gland: correlation with grade of malignancy. Int J Exp Pathol 2010; 91: 10713.

7. Vargas PA, Cheng Y, Barret AW, Craig GT, Speight PM. Expression of Mcm-2, Ki-67 and geminin in benign and malignant salivary gland tumours. J Oral Pathol Med 2003; 37: 309-18.

8. Laguens $\mathrm{G}$, Coronato $\mathrm{S}$, Laguens R, Portianskr E, Girolamo VD. Human regional lymph nodes draining câncer exhibit a profound dendritic cell depletion as comparing to those from patients without malignancies. Immunol Lett 2002; 84: 159-62.

9. Hubert P, Bousarghin L, Greimers R, Franzen-Detrooz E, Boniver J, Delvenne P. Production of large numbers of Langerhans'cells with intraephithelial migration ability in vitro. Exp Dermatol 2005; 14: 469-77. 
10. La Rocca G, Anzalone R, Corrao S, et al. CD1a downregulation in primary invasive ductal breast carcinoma may predict regional lymph node invasion and patient outcome. Histopathology 2008; 52: 203-12.

11. Lin A, Schildknecht A, Nguyen LT, Ohashi PS. Dendritic cells integrate signals from the tumor microenvironment to modulate immunity and tumor growth. Immunol Lett 2009; 127: 77-84.

12. Tsuge $T$, Yamakawa $M$, Tsukamoto $M$. Infiltrating dendritic/Langerhans cells in primary breast cancer. Breast Cancer Res Treat 2000; 59: 141-52.

13. La Rocca G, Anzalone R, Bucchieri F, Farina F, Cappello $\mathrm{F}$, Zummo G. CD1a and antitumour immune response. Immunol Lett 2004; 95: 1-4.

14. O'Donell R, Mick R, Feldman M, et al. Distribution of dendritic cell subtypes in primary oral squamous cell carcinoma is inconsistent with a functional response. Cancer Lett 2007; 255: 145-52.

15. Banchereau J, Briere F, Caux C, et al. Immunobiology of dendritic cells. Annu Rev Immunol 2000; 18: 767-811.

16. Tang A, Amagai M, Granger LG, Stanley JR, Udey MC. Adhesion of epidermal Langerhans cells to keratinocytes mediated by E-cadherin. Nature 1993; 361: 82-5.

17. Heymann R, About I, Lendahl U, Franquin JC, Obrink B, Mitsiadis TA. E- and N-cadherin distribution in developing and functional human teeth under normal and pathological conditions. Am J Pathol 2002; 160: 2123-33.

18. Kohl K, Klein E, Koch S, Schnautz S, Bieber T. Migration and differentiation of Langerhans cell precursors. Eur $J$ Cell Biol 2004; 83: 805-11.

19. Jakob T, Brown MJ, Udey MC. Characterization of E-cadherin-containing junctions involving skin-derived dendritic cells. J Invest Dermatol 1999; 112: 102-8.

20. Economopoulou E, Hanby A, Odell EW. Expression of E-cadherin, cellular differentiation and polarity in epithelial salivary neoplasms. Oral Oncol 2000; 36: 515-8.

21. Yoo J, Park S, Kang CS, Kang SJ, Kim BK. Expression of E-cadherin and p53 proteins in human soft tissue sarcomas. Arch Pathol Lab Med 2002; 126: 33-8.

22. Song $\mathrm{Y}$, Oda $\mathrm{Y}$, Hori $\mathrm{M}$, et al. N-myc downstream regulated gene-1/Cap43 may play an important role in malignant progression of prostate cancer, in its close association with E-cadherin. Hum Pathol 2009; 41: 214 22.

23. Facina G, Lopes-Costa PV, Dos Santos AR, et al. Immunohistochemical expression of E-cadherin in sclerosing adenosis, ductal carcinoma in situ and invasive ductal carcinoma of the breast. Diagn Cytopathol 2009; 38: 235-8.

24. Crocker J, Jenkins R, Campbell J, Fuggle WJ, Shah VM. Immunohistochemical demonstration of S-100 protein in salivary gland neoplasms. J Pathol 1985; 146: 115-21.

25. Kumasa S, Yuba R, Sagara S, Okutomi T, Okada Y, Mori M. Mucoepidermoid carcinomas: immunohistochemical studies on keratin, S-100 protein, lactoferrin, lysozyme and amylase. Basic Appl Histochem 1988; 32: 429-41.

26. Furuse C, Cury PR, Altemani A, Pinto DS Jr, Araujo NS, Araujo VC. $\beta$-Catenin and E-cadherin expression in salivary gland tumors. Int J Surg Pathol 2006; 14: 2127.

27. Prabhu S, Kaveri $\mathrm{H}$, Rekha K. Benign, malignant salivary gland tumors: comparison of immunohistochemical expression of e-cadherin. Oral Oncol 2009; 45: 594-9.

28. Barnes L, Eveson JW, Reichart P, Sidransky D, eds. The World Health Organization's histological classification of tumors. Pathology and genetics of head and neck tumours. Lyon: IARC Press, 2005.

29. Wischatta M, Sprinzl GM, Gunkel AR, Hussl B, Romani N, Schrott-Fischer A. Dendritic cells in selected head and neck tumors. Ann Otol Rhinol Laryngol 2003; 109: 56-62.

30. Riedl E, Stockl J, Majdic O, Scheinecker C, Knapp W, Strobl H. Ligation of E-cadherin in vitro-generated immature Langerhans-type dendritc cells inhibits their maturation. Blood 2000; 96: 4276-84.
31. Lopes FF, da Costa Miguel MC, Pereira AL, et al. Changes in immunoexpression of E-cadherin and betacatenin in oral squamous cell carcinoma with and without nodal metastasis. Ann Diagn Pathol 2009; 13: 22-9.

32. Katabi N, Gomez D, Klimstra DS, Carlson DL, Lee N, Ghossein R. Prognostic factors of recurrence in salivary carcinoma ex pleomorphic adenoma, with emphasis on the carcinoma histologic subtype: a clinicopathologic study of 43 cases. Hum Pathol 2010; 41: 927-34.

33. Kolokythas A, Connor S, Kimgsoo D, Fernandes RP, Ord RA. Low-grade mucoepidermoid carcinoma of the intraoral minor salivary glands with cervical metastasis: report of 2 cases and review of the literature. J Oral Maxillofac Surg 2010; 68: 1396-9.

34. Gabrilovich DI, Chen HL, Girgis KR, et al. Production of vascular endothelial growth factor by human tumors inhibits the functional maturation of dendritic cells. Nat Med 1996; 2: 1096-103.

35. Oyama T, Ran S, Ishida T, et al. Vascular endothelial growth factoraffects dendritic cell maturation through the inhibition of nuclear factor-kappa $\mathrm{B}$ activation in hemopoietic progenitorcells. J Immunol 1998; 160: 1224-32.

36. Coventry B, Heinzel S. CDla in human cancers: a new role for an old molecule. Immunology 2004; 25: 242-8.

37. Lazzaro B, Cleveland D. p53 and Ki-67 antigen expression in small oral biopsy specimens of salivary gland tumors. Oral Surg Oral Med Oral Pathol Oral Radiol Endod 2000; 89: $613-7$

38. Paleri V, Robinson M, Bradley P. Polymorphous lowgrade adenocarcinoma of the head and neck. Curr Opin Otolaryngol Head Neck Surg 2008; 16: 163-9.

39. David R, Buchner A. Langerhans cells in a pleomorphic adenoma submandibular salivary gland. J Pathol 1980; 131: $127-35$

40. Al-Shibli K, Al-Saad S, Donnem T, Persson M, Bremnes RM, Busund LT. The prognostic value of intraepithelial and stromal innate immune system cells in non-small cell lung carcinoma. Histopathology 2009; 55: 301-12.

41. Inoshima N, Nakanishi Y, Minami T, et al. The influence of dendritic cell infiltration and vascular endothelial growth factor expression on the prognosis of non-small cell lung cancer. Clin Cancer Res 2002; 8: 3480-6.

42. Taube JM, Nichols AD, Bornman LS, Bornman DM, Jackson JB. Langerhans cell density and high-grade vulvar intraepithelial neoplasia in women with human immunodeficiency virus infection. J Cutan Pathol 2007; 34: 565-70.

43. Eisenthal A, Polyvkin N, Bramante-Schreiber L, et al. Expression of dendritic cells in ovarian tumors correlates with clinical outcome in patients with ovarian cancer. Hum Pathol 2001; 32: 803-7.

44. Poorten VLM, Baim AJM, Hilgers FJM, Tan IB, Keus RB, Hart AA. Stage as major long term outcome predictor in minor salivary gland carcinoma. Cancer 2000; 89: 1195204.

45. Daa T, Kaku N, Kashima K, Nakayama I, Yokoyama S. Expression of beta-catenin, E-cadherin and cyclin D1 in adenoid cystic carcinoma of the salivary gland. J Exp Clin Cancer Res 2005; 24: 83-7.

46. Shieh YS, Chang LC, Chiu KC, Wu CW, Lee HS. Cadherin and catenin expression in mucoepidermoid carcinoma: correlation with histopathologic grade, clinical stage, and patient outcome. J Oral Pathol Med 2003; 32: 297-304.

47. Araújo VC, Demasi AP, Furuse C, et al. Collagen type I may influence the expression of E-cadherin and betacatenin in carcinoma ex-pleomorphic adenoma. Appl Immunohistochem Mol Morphol 2009; 17: 312-8.

\section{Acknowledgements}

This study was supported by Coordenação de Aperfeiçoamento de Pessoal de Nível Superior (CAPES) 